
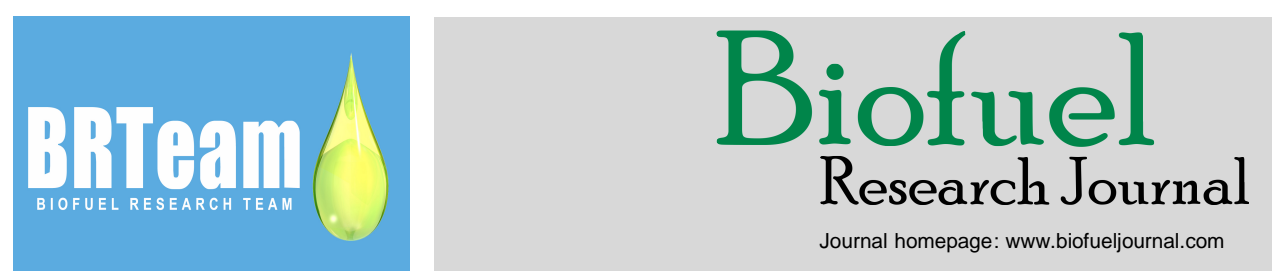

Original Research Paper

\title{
Lipase immobilized on polydopamine-coated magnetite nanoparticles for biodiesel production from soybean oil
}

Marcos F.C. Andrade, Andre L.A. Parussulo, Caterina G.C.M. Netto, Leandro H. Andrade, Henrique E. Toma *

Instituto de Química, Universidade de São Paulo, 05508-000, São Paulo, Brazil.

\section{HIGHLIGHTS}

$>$ Lipase immobilized onto polydopamine magnetite nanoparticle converted soybean oil into biodiesel with high efficiency.

$>$ Polydopamine film allowed direct binding of the enzyme.

$>$ Polydopamine film led to immobilization of a large amount of enzymes onto the magnetic nanoparticles. $>$ The enzyme could be magnetically recycled.

\section{GRAPHICAL ABSTRACT}

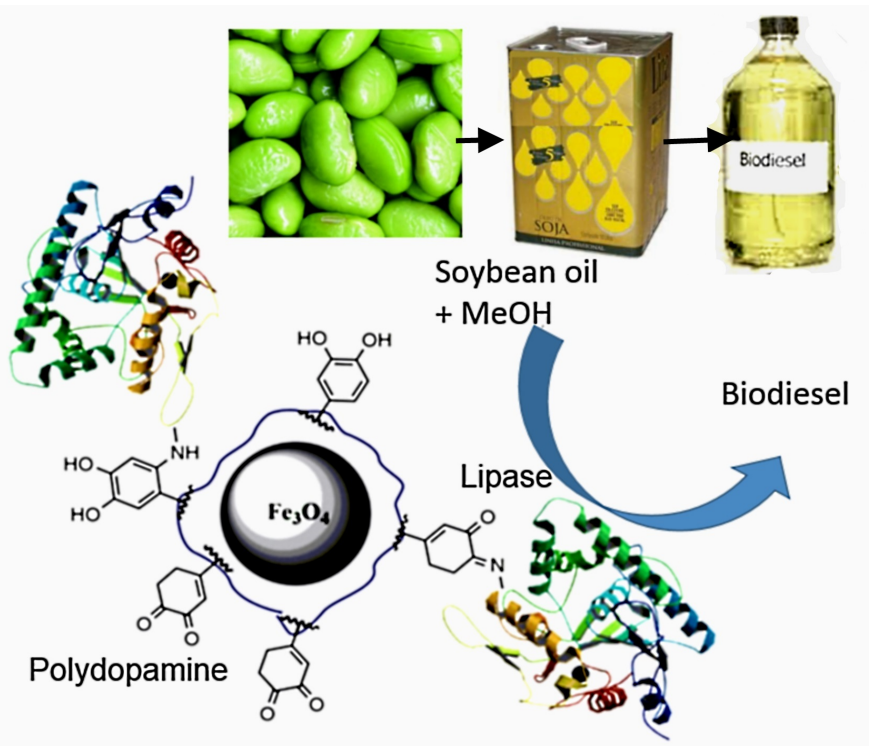

\section{ARTICLE INFO}

\section{Article history:}

Received 12 December 2015

Received in revised form 21 February 2016

Accepted 23 March 2016

Available online 1 June 2016

\section{Keywords:}

Biodiesel

Soybean oil

Lipase

Magnetic nanoparticles

Polydopamine

\begin{abstract}
Lipase from Pseudomonas cepacia was covalently attached to magnetite nanoparticles coated with a thin polydopamine film, and employed in the enzymatic conversion of soybean oil into biodiesel, in the presence of methanol. The proposed strategy explored the direct immobilization of the enzyme via Michael addition and aldolic condensation reactions at the catechol rings, with no need for using specific coupling agents. In addition, a larger amount of enzymes could be bound to the magnetic nanoparticles, allowing their efficient recycling with the use of an external magnet. For biodiesel production, the transesterification reaction was carried out directly in soybean oil by stepwise addition of methanol, in order to circumvent its inactivation effect on the enzyme. A better yield of $90 \%$ was achieved at $37{ }^{\circ} \mathrm{C}$ compared with the free enzyme. However, the immobilized biocatalyst became gradually less effective after the third cycle, due to its prolonged exposition to the denaturating methanol medium.
\end{abstract}

(C) 2016 BRTeam. All rights reserved.

* Corresponding author at: Tel.: +551130913887

E-mail address: henetoma@iq.usp.br

Please cite this article as: Andrade M.F.C., Parussulo A.L.A., Netto C.G.C.M., Andrade L.H., Toma H.E. Lipase immobilized on polydopamine-coated magnetite nanoparticles for biodiesel production from soybean oil. Biofuel Research Journal 10 (2016) 403-409. DOI: 10.18331/BRJ2016.3.2.5 


\section{Introduction}

Biodiesel is an attractive substitute to conventional diesel, conveying significant environmental advantages originated from its renewable feedstocks, i.e., vegetable oils and animal fats. Other benefits include the lower emissions of sulfur-based pollutants, aerosols, and carbon monoxide compared with the petrochemical products (Sharp et al., 2000; Shrivastava et al., 2000). Currently, production of biodiesel is carried out by means of the transesterification reaction, employing corrosive chemical catalysts (strong acids or bases) at relatively high temperatures (Moser, 2011). Hence, the downstream processing costs and environmental issues have led to a search for alternative eco-friendly biodiesel production methods (Kim et al., 2006; Hama et al., 2007; Bisen et al., 2010; Verma et al., 2013).

In this context, lipases have been proposed as a feasible alternative to sodium hydroxide or sulfuric acid (Moser, 2011). Enzyme-mediated processes are considered more advantageous over the chemical routes, since they proceed at room temperature and do not practically away triger environmental concerns (Tan et al., 2010; Li et al., 2011; Atabani et al., 2012; Verma et al., 2013). In addition, enzymes can achieve high catalytic efficiencies under brand reaction conditions, and moreover, due to substrate specific, they are regarded as very attractive alternatives to the chemical processes. However, enzymes are also easily denatured entities and their short catalytic lifespan and high prices inevitably limit their applications in large-scale reactors. For this reason, there is a great interest in immobilizing enzymes on solid supports, allowing recyclability while substantially reducing the catalyst cost (Katchalski-Katzir, 1993; Straathof et al., 2002; Mateo et al., 2007; Hanefeld et al., 2009; Bose et al., 2010; Rebelo et al., 2010; Garcia-Galan et al., 2011; Wang et al., 2011; Yucel et al., 2011; Rodrigues et al., 2013). Re-usage is not the only advantage of enzyme immobilization and it has been previously reported that immobilized enzymes can exhibit higher reaction rates and better thermal stability compared with their free counterparts (Verma et al., 2013).

The advantages of nanomaterials as support for enzyme immobilization have opened new perspectives in biocatalysis arena. Such nanomaterials should be engineered by controlling the size, shape, and functionalization, in order to improve their suitability for applications in nanobiocatalysis. In fact, the nanoscale dimension of the nanoparticles ensures a very good partnership with enzymes, allowing their association and performance as new modified species, keeping their mobility and mass transfer characteristics in solution, but incorporating better qualities in terms of stability and activity.

In particular, the use magnetic nanoparticles is especially rewarding, for allowing easy enzyme recovery by applying an external magnet. Supermagnets of $\mathrm{Nd}_{2} \mathrm{Fe}_{14} \mathrm{~B}$ displaying strong magnetic fields are quite available in the market, and are suitable for this purpose. However, one has to carefully consider the biomolecule linking procedure to the nanoparticle beforehand, since the coupling method can impact the enzyme catalytic activity and its immobilization efficiency (Rebelo et al., 2010; Netto et al., 2009, 2011, 2012, 2013, 2015). A large variety of methods has already been employed (Netto et al., 2013); however, they have led to very contrasting results.

In this regard, polydopamine was recently introduced as a very promising material for the immobilization of biomolecules in inorganic substrates (Xu et al., 2004; Lee et al., 2007; 2009; Ren et al., 2011; Black et al., 2013). This bio-inspired polymer is easily formed by the partial oxidation of dopamine in a mild alkaline medium, and exhibits high affinity for most inorganic surfaces. Its great attractiveness offers not only a fast and easy way to coat magnetite nanoparticles, but also the possibility of direct attachment of the biomolecules, by means of Michael addition or aldolic condensation reactions at its exposed catechol rings.

Among the inorganic supports used for the attachment of proteins, many interesting advantages could be achieved by using magnetite nanoparticles (Netto et al., 2013). Superparamagnetic materials allow a convenient separation of the catalyst from the reaction medium by simply using an external magnetic field. In addition, their large surface area allows the adsorption of high amounts of biomolecules, while the nanoparticulate nature provides a good mobility for catalysis. Other important aspects such as higher stability and environmental compatibility should also be mentioned. However, as Verma et al. (2013) pointed out, in the case of nanomaterials bound enzymes used in catalyzed biofuel production, there are yet many aspects to be explored and improved, as their large-scale use is still in their infancy.

In this sense, a successful association of lipase with a versatile coating polymer such as polydopamine and a superparamagnetic particle (magnetite), has already been reported in the literature (Xu et al., 2004 Lee et al., 2007; 2009; Ren et al., 2011; Black et al., 2013), but to the best of our knowledge, its application in biofuel production has never been attempted. This is rather surprising, since lipases are well-known candidates in bio-catalyzed biodiesel synthesis (Kim et al., 2006; Hama et al., 2007; Bisen et al., 2010; Li et al., 2011; Wang et al., 2011; Atabani et al., 2012; Verma et al., 2013). As a matter of fact, the immobilization of lipase on silver nanoparticles via adhesive polydopamine for biodiesel production has already been successfully reported (Dumri et al., 2014). However, in this case, the enzyme recycling was found not feasible, and moreover, the generation of silver contaminants could raise serious environmental concerns. Therefore, the use of Pseudomonas cepacia lipase immobilized on polydopamine coated $\mathrm{Fe}_{3} \mathrm{O}_{4}$ nanoparticles to perform the bio-catalytical synthesis of biodiesel was explored in the present study. Biodiesel was produced using the immobilized nanobiocatalyst, soybean oil, and methanol under environmentally-compatible conditions. Such initiative is in line with the modern trends in sustainable biotechnology, and could be particularly of interest for soybean biodiesel producing countries.

\section{Materials and Methods}

Lipase from $P$. cepacia (powder), $\mathrm{FeCl}_{3} .6 \mathrm{H}_{2} \mathrm{O}, \mathrm{FeCl}_{2} .4 \mathrm{H}_{2} \mathrm{O}, \mathrm{NaOH}$ $\mathrm{NaH}_{2} \mathrm{PO}_{4} \cdot \mathrm{H}_{2} \mathrm{O}$, dopamine hydrochloride, and Bradford reagent solution were obtained from Sigma-Aldrich (Germany). Methanol was purchased from Synth (Brazil). A commercially-available refined soybean oil produced by Lisa Company (Brazil) was used in all transesterification reactions.

Bradford essays were performed using a HP8453 diode array (190$1100 \mathrm{~nm}$ ) spectrophotometer. Transmission electron microscopy (TEM) images were obtained using a JEOL JEM 2100 equipment employing a $\mathrm{LaB}_{6}$ emission filament, with $200 \mathrm{kV}$ maximum acceleration tension. A Bruker Eco-ATR with a Ge crystal was used to obtain the FT-IR spectra. For atomic force microscopy, a Nanoscope E from Digital Instruments was used.

\subsection{Magnetite nanoparticles synthesis}

The magnetite nanoparticles were synthesized using a previously described method (Yamaura et al., 2004) involving the coprecipitation of $\mathrm{Fe}^{3+}$ and $\mathrm{Fe}^{2+}$ hydroxides, in an alkaline medium. More specifically, a system containing $200 \mathrm{~mL}$ of a $1 \mathrm{~mol} \mathrm{~L}^{-1} \mathrm{NaOH}$ aqueous solution was initially deoxygenated, and was mechanically stirred at $1100 \mathrm{rpm}$. Then, $50 \mathrm{~mL}$ of $0.2 \mathrm{~mol} \mathrm{~L}^{-1} \mathrm{FeCl}_{3}$ and $0.1 \mathrm{~mol} \mathrm{~L}^{-1} \mathrm{FeCl}_{2}$ solution were added drop-wise. The reaction was allowed to proceed for $30 \mathrm{~min}$ at room temperature. Subsequently, the black precipitate was magnetically separated and washed 5 times with nano-pure water.

\subsection{Nanoparticles functionalization with polydopamine}

The freshly-prepared magnetite nanoparticles were dispersed in 100 $\mathrm{mL}$ of distilled water, and $250 \mathrm{mg}$ of dopamine hydrochloride was added The $\mathrm{pH}$ was adjusted to 8.4 using a $1 \mathrm{~mol} \mathrm{~L}^{-1} \mathrm{NaOH}$ aqueous solution. The dispersion was air-bubbled for $3 \mathrm{~h}$, at $30 \mathrm{~min}$ intervals. The particles were again magnetically separated and rinsed 3 times with distilled water.

\subsection{Immobilization of lipase from $\mathrm{P}$. cepacia on $\mathrm{Fe}_{3} \mathrm{O}_{4} @$ polydopamine}

For lipase immobilization, the general procedure described by Ren et al. (2011) was used. The polydopamine coated magnetite nanoparticles $\left(\mathrm{Fe}_{3} \mathrm{O}_{4} @ \mathrm{PD}\right)$ were dispersed in $100 \mathrm{~mL}$ of $10 \mathrm{mM}$ PBS at pH 7. Then, 4 $\mathrm{mL}$ of this dispersion was cooled at $4{ }^{\circ} \mathrm{C}, 200 \mathrm{mg}$ of the lipase powder was added, and the system was stirred for $1 \mathrm{~h}$ at $4{ }^{\circ} \mathrm{C}$. The black powder was magnetically separated, washed with distilled water, and dried overnight under reduced pressure. 
2.4. Biodiesel synthesis catalyzed by lipase from P. cepacia immobilized on magnetic nanoparticles

The transesterification reaction was carried out directly in soybean oil and methanol, with no need for additional solvents, as expected for a green strategy. Initially, $200 \mathrm{mg}$ of the nanocatalyst was added to $1 \mathrm{~g}$ of a 1:1 $(\mathrm{mol} / \mathrm{mol})$ mixture of methanol and soybean oil, and the system was agitated at $37{ }^{\circ} \mathrm{C}$ for $12 \mathrm{~h}$. Then, 3 equivalents of methanol (relative to the initial amount of soybean oil) were added in two steps, after 150 and $300 \mathrm{~min}$ of the reaction. Finally, the particles were magnetically separated, washed with tertbutanol, and dried under reduced pressure for $10 \mathrm{~min}$.

\subsection{ATR-FTIR biodiesel quantification in soybean oil / biodiesel mixtures}

The amount of biodiesel present in mixture with soybean oil was determined by adapting a fast and reliable method proposed in the literature (Mahamuni et al., 2009; Zhang et al., 2013). More specifically, the method was based on monitoring the intensities $\mathrm{CH}_{3}$ asymmetric stretching signals (characteristic of fatty acids methyl ester infra-red spectra) as a function of biodiesel to soybean oil mass ratio. For this purpose, a highly pure biodiesel reference material was employed and standard biodiesel/soybean oil mixtures were prepared in order to construct a calibration curve correlating the intensity (area) of $1427-1450 \mathrm{~cm}^{-1}$ band and the biodiesel percentage as shown in Figure 1.
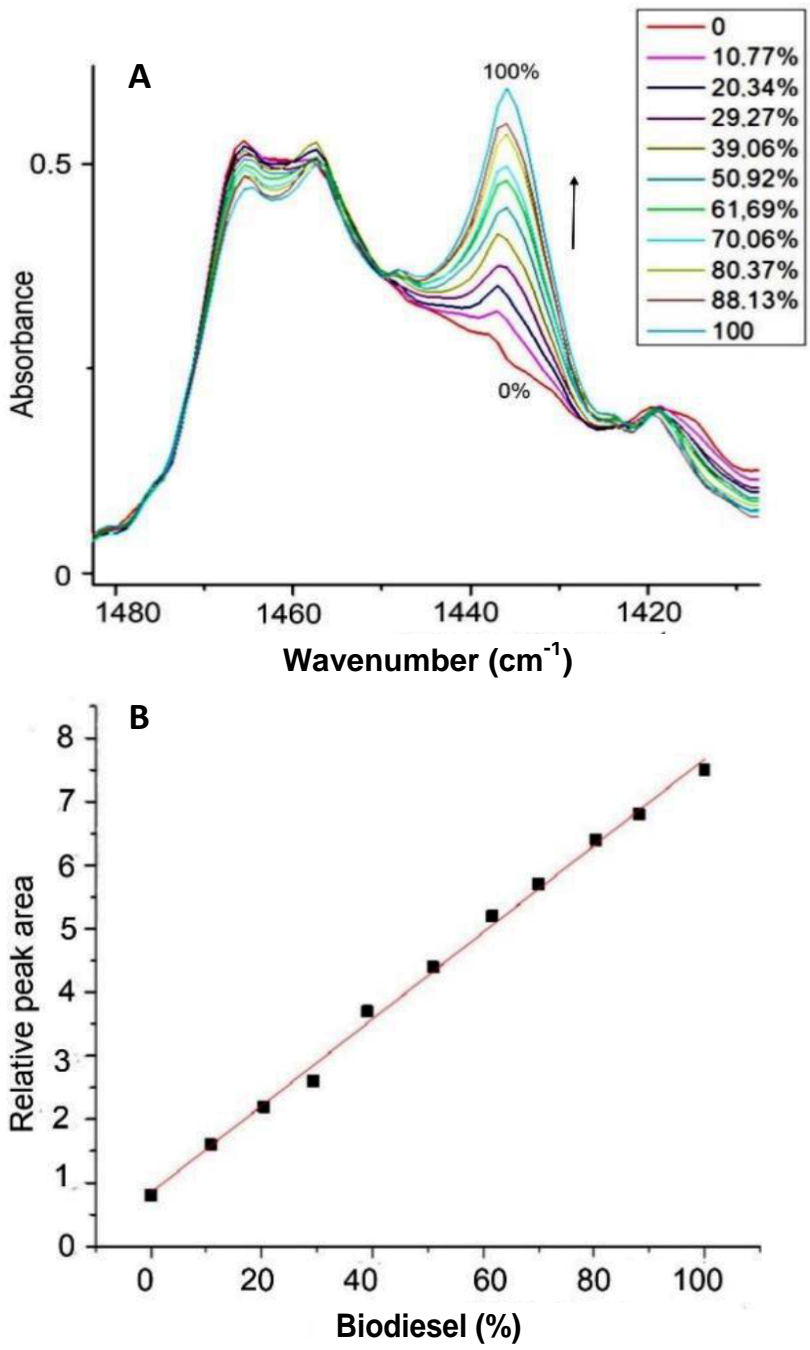

Fig.1. (A) FTIR spectra of soybean oil / biodiesel mixtures. The box on the top right indicates the mass percentage of biodielsel in the sample. (B) Calibration curve made by correlating the area under $1427-1450 \mathrm{~cm}^{-1}$ band and the relative mass of biodiesel in the soybean oil / biodiesel solutions.

\section{Results and discussion}

Dynamic light scattering measurements for the $\mathrm{Fe}_{3} \mathrm{O}_{4}$ nanoparticles in aqueous solution revealed a typical hydrodynamic radius distribution of around $86 \mathrm{~nm}$ (Fig. 2A). Such average distribution actually involves aggregates of smaller nanoparticles which are of interest in enzymatic catalysis. This is ascribed to the fact that they exhibit a rather strong magnetization behavior, thus responding more rapidly to the applied magnetic fields. After the treatment with dopamine, the average hydrodynamic radius was increased to $112 \mathrm{~nm}$ (Fig. 2B), reflecting the polymeric coating around the $\mathrm{Fe}_{3} \mathrm{O}_{4}$ nanoparticles.
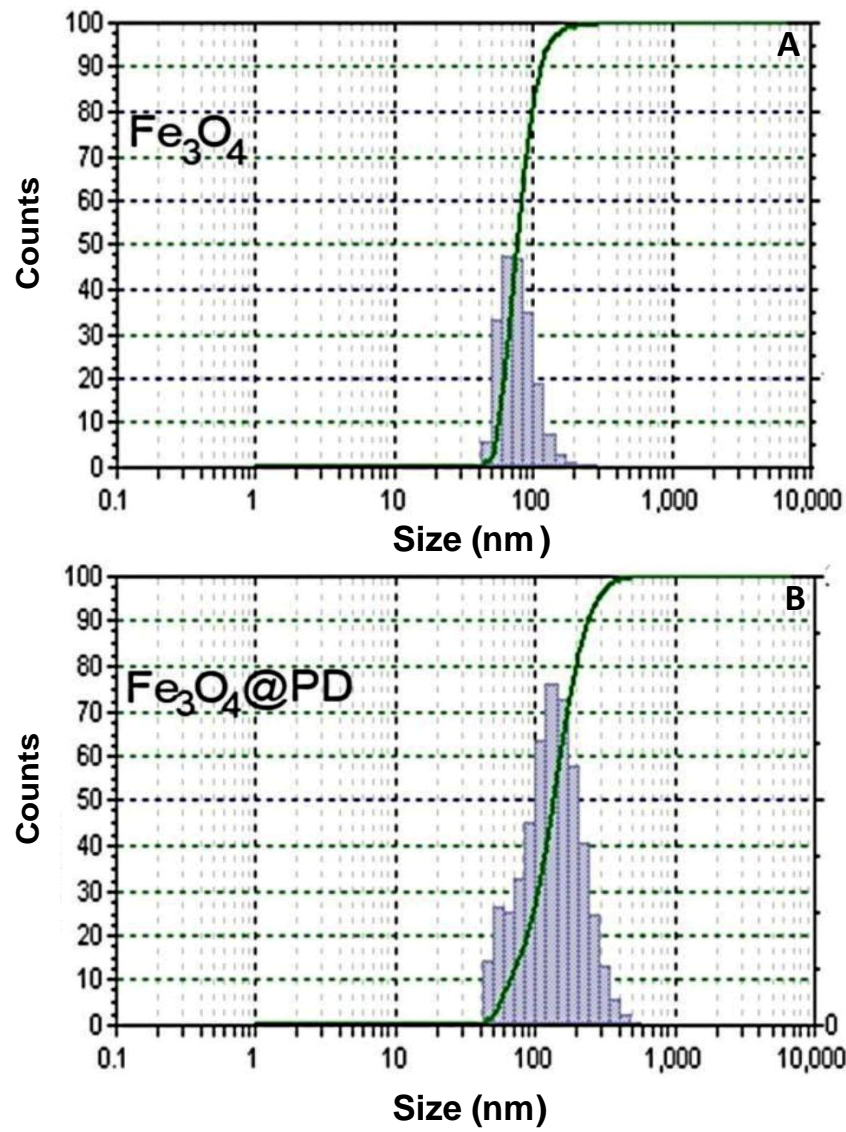

Fig.2. DLS profiles for the $\mathrm{Fe}_{3} \mathrm{O}_{4}$ (A) and $\mathrm{Fe}_{3} \mathrm{O}_{4} @ \mathrm{PD}$. (B) nanoparticles in aqueous solution.

The AFM images of $\mathrm{Fe}_{3} \mathrm{O}_{4} @$ PD nanoparticles, in the contact mode and in the phase contrast mode, can be seen in Figures $3 \mathrm{~A}$ and $3 \mathrm{~B}$, respectively, corroborating the results obtained from the DLS measurements. In the phase contrast image, it is possible to detect the aggregated clusters core surrounded by a soft material attributed to the polydopamine film coating. In the corresponding TEM images, a large amount of $\mathrm{Fe}_{3} \mathrm{O}_{4}$ aggregates comprising typical $11 \mathrm{~nm}$ magnetic cores could be observed (Fig. 4 A and B). As shown in Figure 4B, it can be concluded that the sample preparation caused the magnetite nanoparticles be surrounded by an amorphous and almost transparent film, which is completely absent in Figure 4A.

The FTIR spectra of the $\mathrm{Fe}_{3} \mathrm{O}_{4}$ and $\mathrm{Fe}_{3} \mathrm{O}_{4} @ \mathrm{PD}$ nanoparticles can be seen in Figure 5. By comparing these images, magnetite functionalization with polydopamine represented by the presence of three sharp peaks, i.e., aromatic C-C stretching $\left(1486 \mathrm{~cm}^{-1}\right), \mathrm{NH}_{3}$ in-plane bending $\left(1422 \mathrm{~cm}^{-1}\right)$, and $\mathrm{C}-\mathrm{O}-\mathrm{H}$ symmetric bending $\left(1266 \mathrm{~cm}^{-1}\right)$ could be detected. In fact, the presence of these bands represents the presence of polydopamine, however, it is worth noticing that at the present time there is no general agreement about the real structure of this particular coating material (Liebscher et al., 2013). 

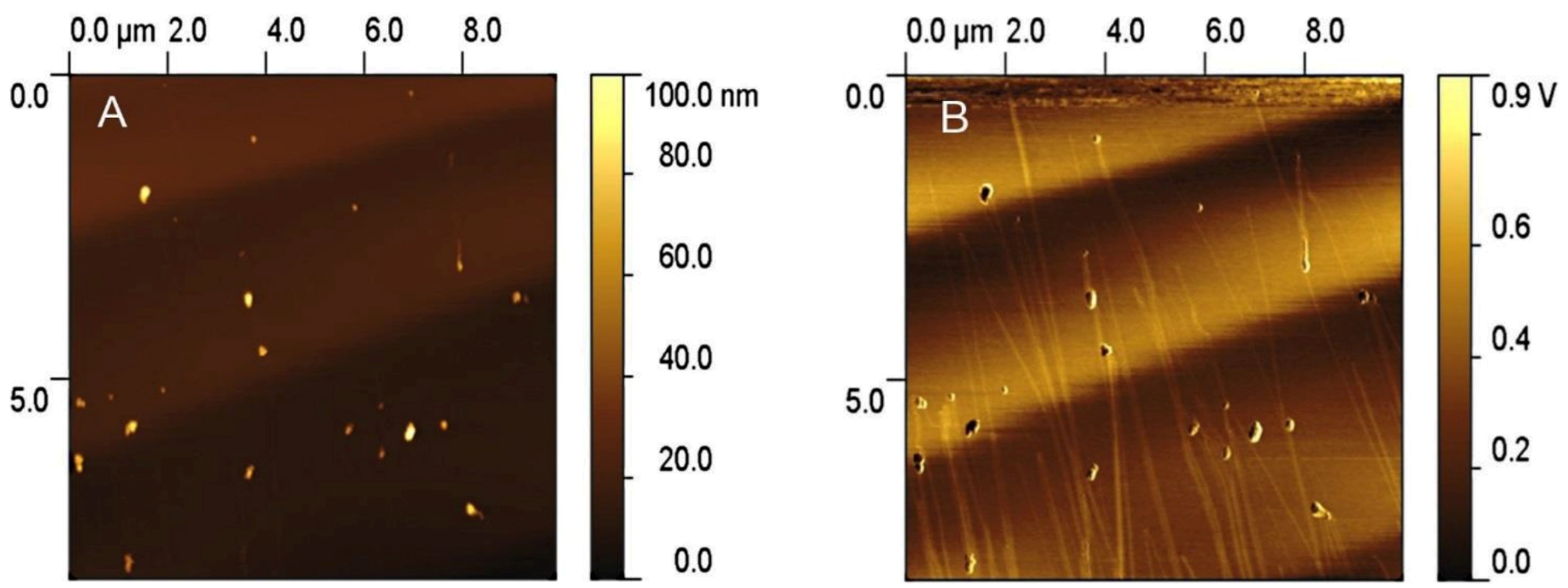

Fig.3. (A) Contact mode AFM and (B) Phase contrast AFM of magnetite nanoparticles coated with polydopamine.

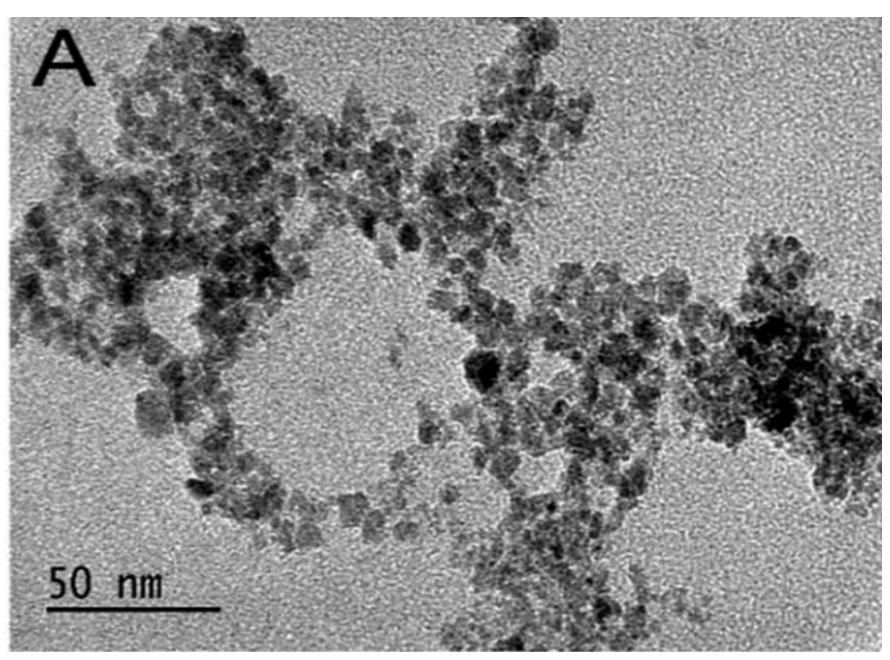

Fig.4. TEM images of (A) $\mathrm{Fe}_{3} \mathrm{O}_{4}$ and (B) $\mathrm{Fe}_{3} \mathrm{O}_{4} @ P D$ nanoparticles.

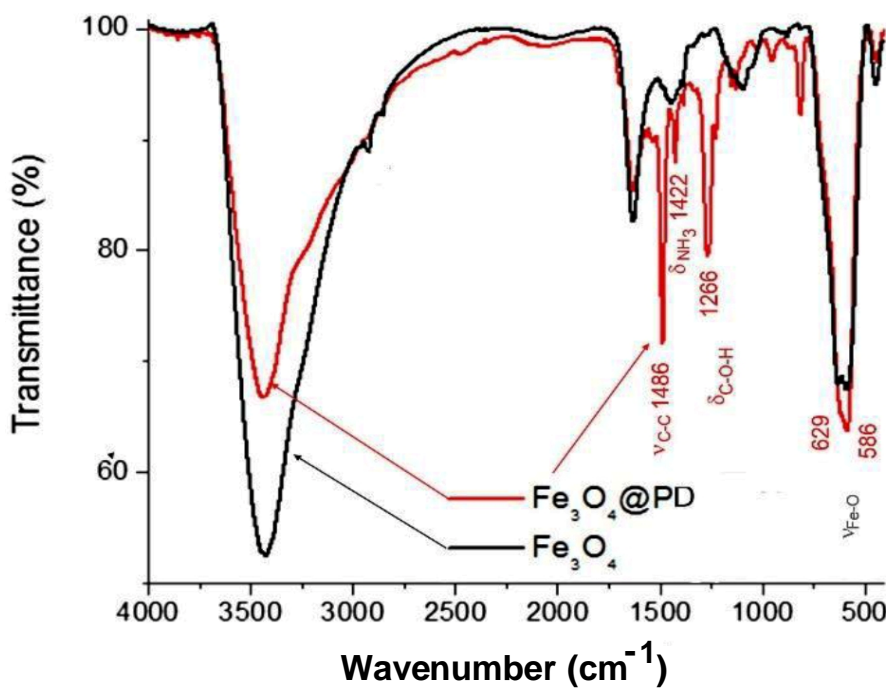

Fig.5. FTIR spectra spectra of bare and polydopamine - coated magnetite nanoparticles.

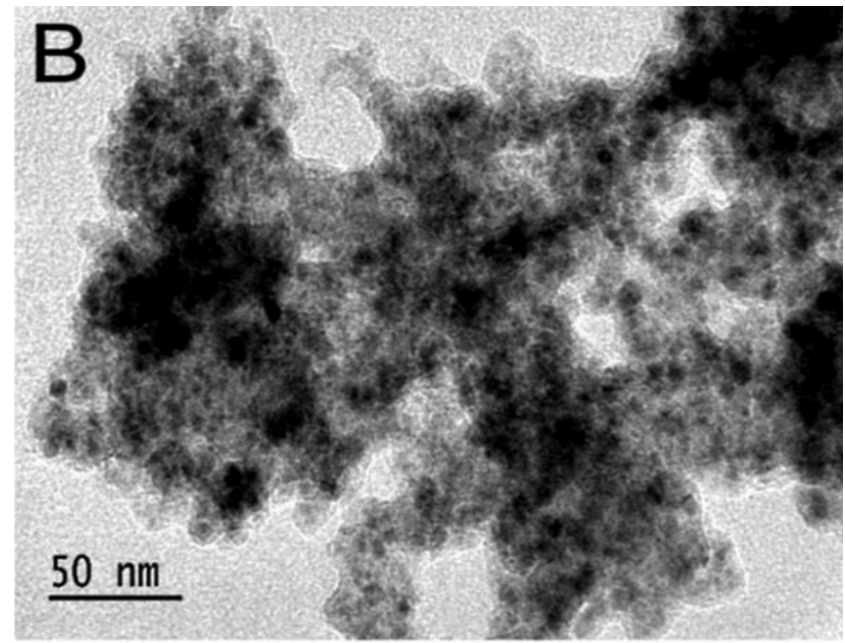

Polydopamine allows an easy immobilization of biomolecules by means of Michael addition or aldolic condensation reactions at the catecholic ring. This possibility entirely dispenses the use of linking agents such as EDC and glutaraldehyde (Fig. 6). Moreover, it also readily polymerizes over a wide range of materials in the presence of molecular oxygen.

Hence, lipase from $P$. cepacia was easily immobilized on $\mathrm{Fe}_{3} \mathrm{O}_{4} @ \mathrm{PD}$ without using any additional linking agents and previous treatments of the lipase powder. The reaction was accomplished within $10 \mathrm{~min}$ and such fast chemical binding has a great advantage, i.e., decreased the risk of enzyme denaturation as it is the case when more drastic procedures are employed.

Distinct differences in the FTIR spectra from the vibrational bands in the $1100-1700 \mathrm{~cm}^{-1}$ region can be noticed before and after the protein immobilization procedure (Figs. 5 and 7). These differences were ascribed to the covalent attachment of the enzyme to the nanomaterial. Nevertheless, the assignment of the vibrational peaks was not feasible, because of the strong superimposition of the polydopamine and lipases spectra in this region. However, all non-adsorbed enzymes in the fina material was completely discarded by rinsing three times with $\mathrm{PBS}, \mathrm{pH} 7$.

The main interest to covalently attach the lipases on magnetite nanoparticles surfaces is attributed to the easy separation of the catalyst from the solution. Another advantage of this attractive material is its recyclability. Therefore, both the catalytic efficiency of the immobilized 


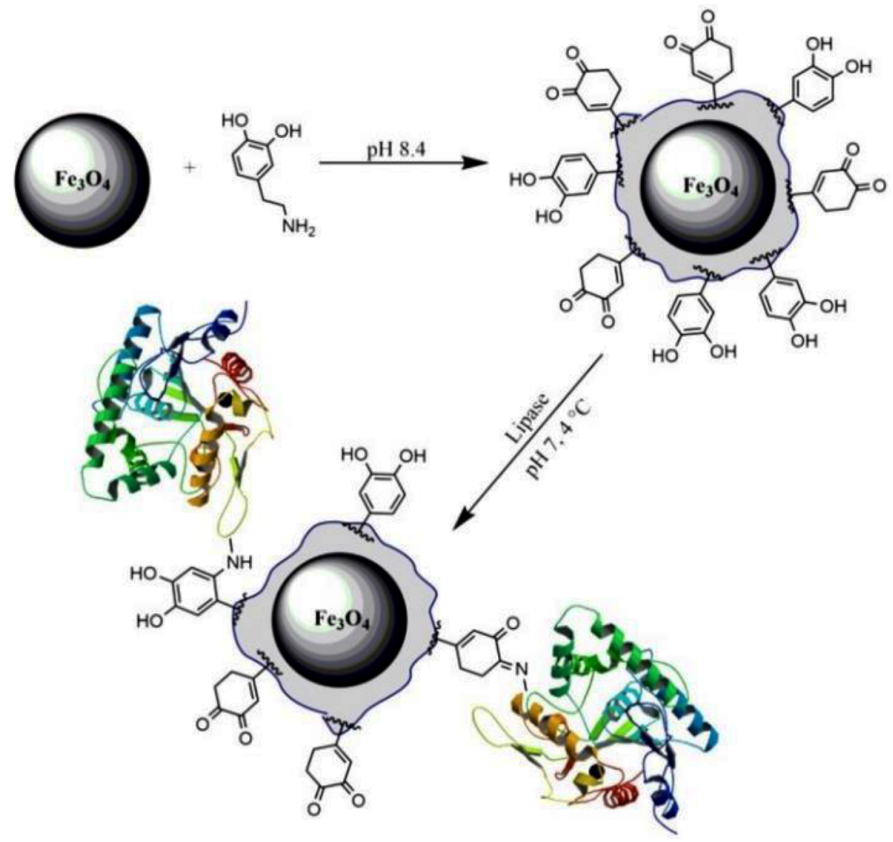

Fig.6. Schematic illustration of the magnetite coating by in-situ polymerization of dopamine at the nanomaterial surface, and the binding of lipase by means of the Michael addition or aldolic condensation involving the amino groups of the exposed catechol groups. The irregular form (in gray) around the $\mathrm{Fe}_{3} \mathrm{O}_{4}$ spheres represents the polydopamine film and the enzyme is represented by colored structures.

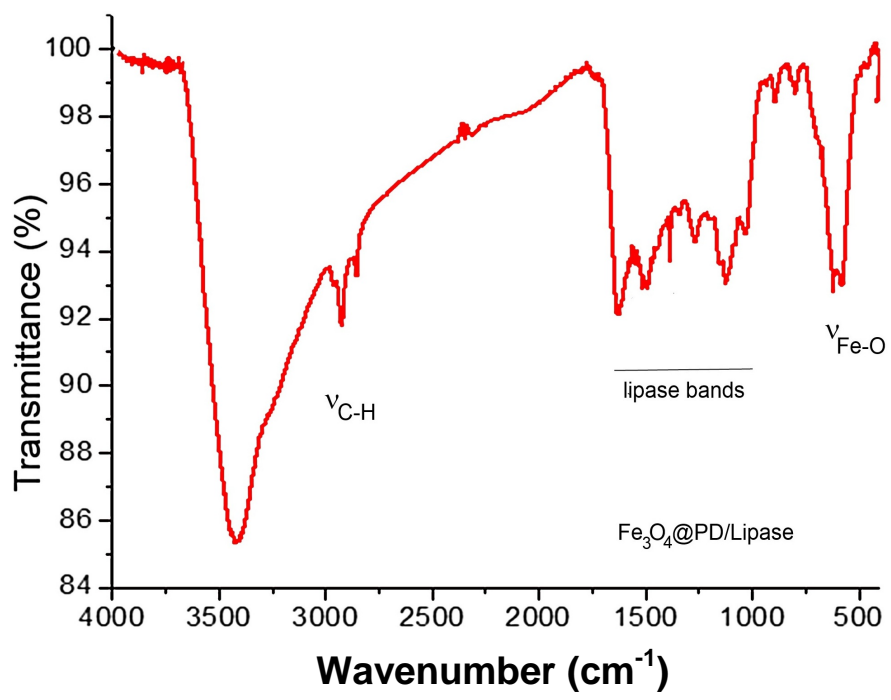

Fig.7. FTIR spectrum of $\mathrm{Fe}_{3} \mathrm{O}_{4} @ \mathrm{PD}$-Lipase showing the characteristic enzyme vibrational peaks in the $1100-1700 \mathrm{~cm}^{-1}$ range.

enzyme and its activity during 5 successive reaction cycles were investigated herein.

Prior to biodiesel synthesis, the conditions for lipase immobilization at the polydopamine shell around the magnetite nanoparticles were optimized. More specifically, the effect of the dopamine/magnetite mass ratio on the amount of lipase adsorbed on the functionalized nanomaterial was first investigated. Accordingly, as shown in Figure 8, the amount of immobilized lipase did not increase linearly with increasing the dopamine/magnetite mass ratio, but exhibited a saturation behavior when the ratio was above 2 . For this reason, this condition was selected to coat magnetite nanoparticles with polydopamine. At the second step, the concentration of $\mathrm{Fe}_{3} \mathrm{O}_{4} @ \mathrm{PD}$ in the medium containing lipase was changed to maximize both enzyme adsorption efficiency and the protein relative mass in the nanocatalyst. These experiments were carried at a constant initial mass of enzymes of $0.077 \mathrm{mg}, 10 \mathrm{mmol} \mathrm{L}^{-1}\left(\mathrm{pH} 7\right.$, PBS solution) at $4{ }^{\circ} \mathrm{C}$ and by using different $\mathrm{Fe}_{3} \mathrm{O}_{4} @ \mathrm{PD}$ concentrations.

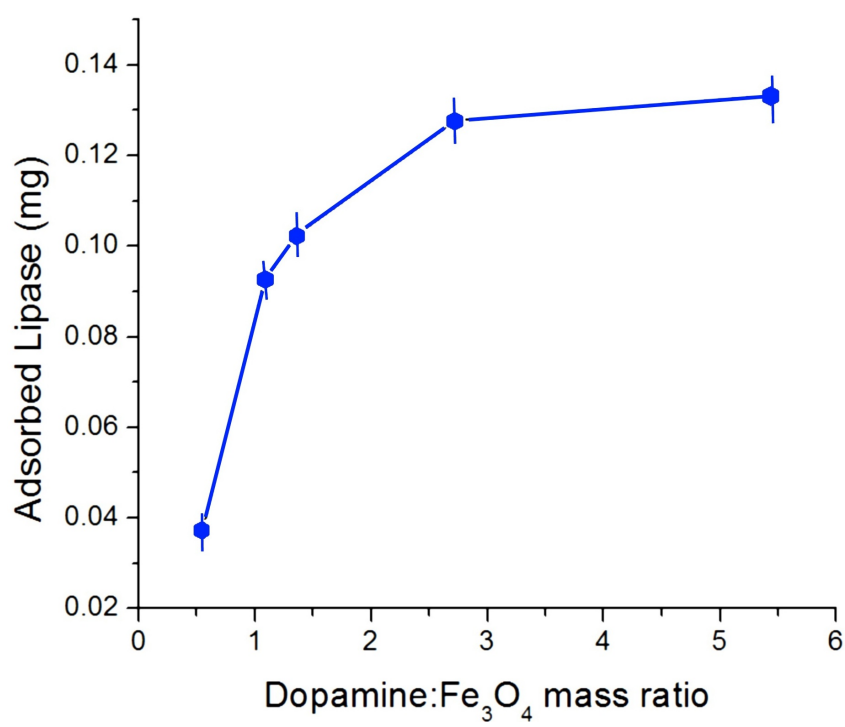

Fig.8. Maximum amount of lipase adsorbed as a function of dopamine to magnetite mass ratio.

The analysis of the data presented in Figure 9 readily indicates that although higher nanoparticle to lipase ratios resulted in higher adsorption of the protein, for a constant mass of enzyme, the relative amount of lipase in the final nanocatalyst decreased by increasing the $\mathrm{Fe}_{3} \mathrm{O}_{4} @ \mathrm{PD}$ concentration, probably because of the redistribution effect. So, in the next sequence of the experiments, $2 \%$ enzyme load was used as a good compromise between adsorption efficiency and the relative amount of lipase in the material.

After the optimization of lipase chemical adsorption onto the functionalized nanomaterials, the enzyme activity was evaluated in the transesterification of soybean oil with methanol in a solvent-free reaction. A major concern with this reaction is the irreversible denaturation of lipases by insoluble methanol in the reaction media, as equimolar proportions of soybean oil and methanol are used. Unfortunately, this problem is inherent in the lipase-based biodiesel production systems and represents a critical challenge to be overcome, regardless of the immobilization process employed. As an attempt to circumvent the problem, several experiments under variable flow conditions were performed in the present study, in order to minimize the exposition of lipase to the denaturating condition. Since such experiments could be intrinsically more complicated by reproducibility problems and by introducing more variables in the process. Hence, an alternative procedure was adopted herein by stepwise addition of methanol to the soybean oil. The immobilized lipase was initially added in an equimolar mixture of methanol and soybean oil (near the solubility limit of methanol in SBO). The remaining equivalents of methanol were equally added in two steps, after 150 and $300 \mathrm{~min}$. A higher solubility of methanol in biodiesel compared with its solubility in soybean oil validates this approach. The proposed protocol is illustrated in Figure 10, where the dashed lines and arrows indicate the points when methanol was added to the reaction media.

During the first reaction cycle at $37{ }^{\circ} \mathrm{C}$, the immobilized enzyme converted $93 \%$ of soybean oil into biodiesel after $12 \mathrm{~h}$ reaction, which was better than the result obtained using the free enzyme $(86 \%)$ under the same reaction conditions. This result corroborates the general observation in immobilized enzyme cataysis, that the enzyme activity is improved when compared with its free counterpart (Netto et al., 2009; 2010; 2011). 

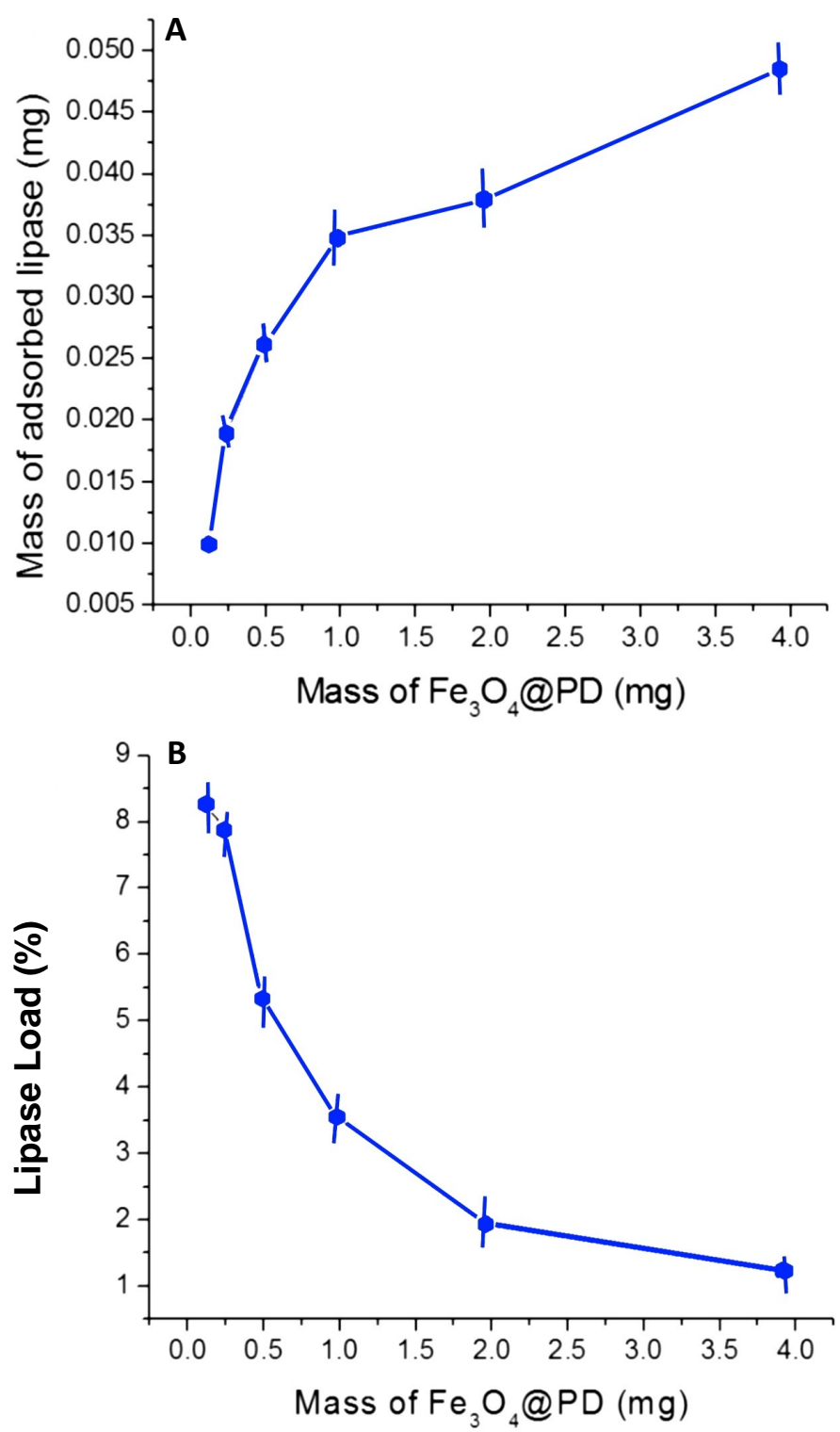

Fig.9. (A) Mass of adsorbed lipase and (B) relative mass of lipase on the nanocatalyst as a function of the initial mass of the functionalized nanomaterial. Experiments were carried in 10 $\mathrm{mM}(\mathrm{pH} 7, \mathrm{PBS})$ at $4^{\circ} \mathrm{C}$ and lipase initial mass of $0.077 \mathrm{mg}$.

Although the catalyst achieved a high soybean oil into biodiesel conversion during the first reaction, the efficiency of the transesterification reaction gradually decreased in the subsequent cycles, particularly after the third cycle (Fig. 11). This might be due to the prolonged exposition of the enzyme to the medium containing high methanol concentration. In fact, both temperature and methanol concentration can be responsible for slow denaturation of the immobilized protein, and this aspect should be more deeply investigated. In spite of this, the use of the superparamagnetic nanoparticles functionalized with polydopamine during the first three cycles was very successful in terms of the yield achieved.

\section{Conclusions}

Lipase from $P$. cepacia was readily adsorbed onto magnetite nanoparticles coated with a thin polydopamine film, with no need for using additional linking agents, thus ensuring a green procedure. The immobilized lipase led to a higher soybean oil conversion of $93 \%$ into biodiesel within $12 \mathrm{~h}$ than the free enzyme $(86 \%)$. The reaction could be carried out directly in soybean oil and methanol as reactants, without using any additional solvents, encompassing another relevant green aspect to be mentioned. The magnetic nanocatalyst could be recycled at least three times by coupling the process with a stepwise addition of methanol during the $12 \mathrm{~h}$ solventfree reaction at $37{ }^{\circ} \mathrm{C}$. The findings of the present study revealed that enzymatic catalysis could be effectively applied for biodiesel synthesis fulfilling the expectations considered for a green chemistry strategy by employing a recyclable natural catalyst under environmentally-friendly conditions, in contrast with the industrial processes currently in-use.

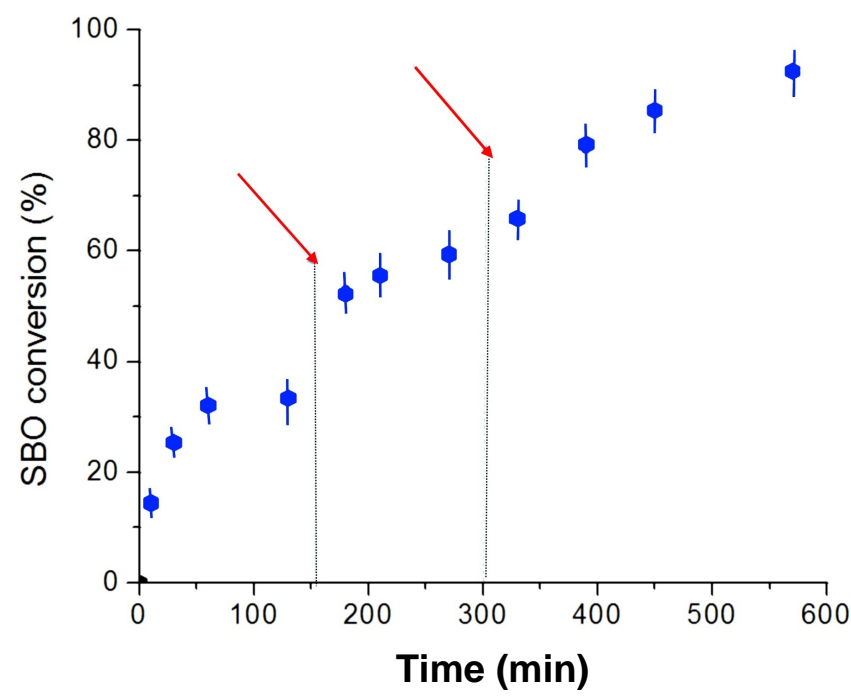

Fig.10. Percentage of soybean oil conversion into biodiesel using $20 \%$ of nanocatalys mass relative to the initial mass of the reactants. Dashed lines and arrows indicate the stepwise addition of 3 mole equivalents of methanol relative to soybean oil.

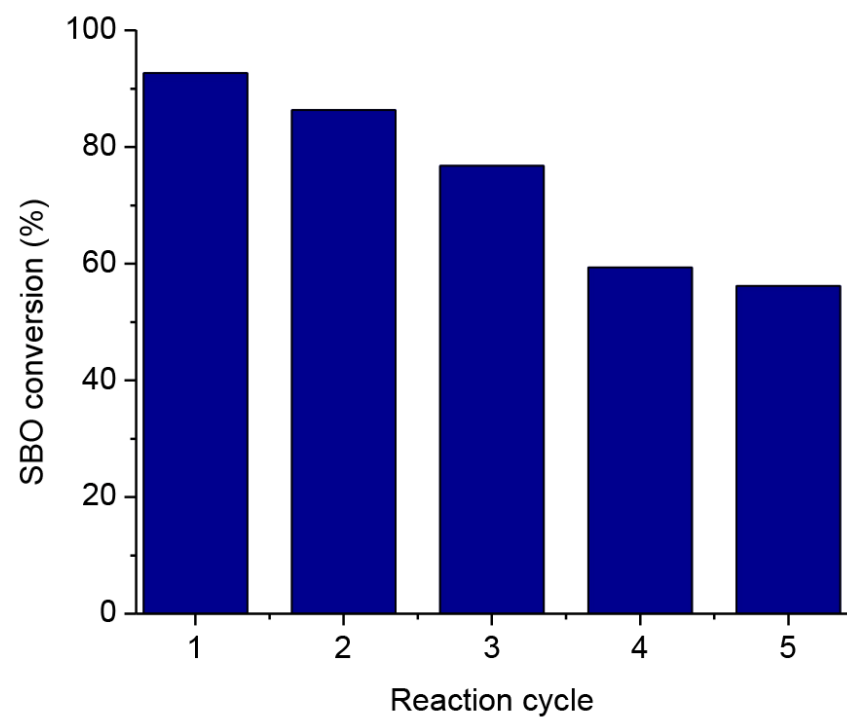

Fig.11. Total amount of SBO converted into biodiesel after $12 \mathrm{~h}$ reaction at $37{ }^{\circ} \mathrm{C}$ in a solvent free reaction. The immobilized enzyme was recycled up to 5 times and the amount of SBO converted at each cycle is presented.

\section{Acknowledgements}

The support from Fundação de Amparo à Pesquisa Científica e Tecnologica, FAPESP - Grant 2013/24725-4, and Conselho Nacional de Desenvolvimento Científico e Tecnológico, CNPq, Grant 482383/2013-5 is gratefully acknowledged. 


\section{References}

[1] Atabani, A.E., Silitong, A.S., Badruddin, I.A., Mahlia, T.M.I., Masjuki, H.H., Mekhilef, S.A., 2012. Comprehensive review on biodiesel as an alternative energy source and its characteristics. Renew. Sust. Energy Rev. 16, 2070-2093.

[2] Bisen, P.S., Sanodiya, B.S., Thakur, G.S., Baghed, R.K., Prasad, G.B., 2010. Biodiesel production with special emphasis on lipase-catalised transesterification. Biotechnol. Lett. 32, 1019-1030.

[3] Black, K.C., Yi, J., Rivera, J.G., Zelasko-Leon, D.C., Messersmith, P.B., 2013. Polydopamine-enabled surface functionalization of gold nanorods for cancer cell-targeted imaging and phothermal therapy. Nanomedicine. 8, 17-28.

[4] Bose, S., Armstrong, D.W., Petrich, J.W., 2010. Enzyme-catalyzed hydrolysis of cellulose in ionic liquids: a green approach toward the production of biofuels. J. Phys. Chem. B. 114, 8221-8227.

[5] Dumri, K., Hung-Anh, D., 2014. Immobilization of lipase on silver nanoparticles via adhesive polydopamine for biodiesel production. Enzyme Res. Article ID 389739

[6] Garcia-Galan, C., Berenguer-Murcia, A., Fernandez-Lafuente, R., Rodrigues, R.C., 2011. Potential of different enzyme immobilization strategies to improve enzyme performance. Adv. Synth. Catal. 353, 2885-2904.

[7] Hama, S., Yamaji, H., Fukumizu, T., Numata, T., Tamalampudi, S., Kondo, A., Noda, H., Fukuda, H., 2007. Biodiesel-fuel production in a packed-bed reactor using lipase-producing Rhizopus oryzae cells immobilized within biomass support particles. Biochem Eng. J. 34, 273278

[8] Hanefeld, U., Gardossi, L., Magner, E., 2009. Understanding enzyme immobilization. Chem. Soc. Rev. 38, 453-468.

[9] Katchalski-Katzir, E., 1993. Immobilized enzymes learning from past successes and failures. Trends Biotechnol. 11, 471-478.

[10] Kim, J., Jia, J., Wang, P., 2006. Challenges in biocatalysis for enzyme based biofuel cells. Biotechnol. Adv. 24, 296-308

[11] Lee, H., Dellatore, S.M., Miller, W.M., Messersmith, P.B., 2007. Mussel inspired surface chemistry for multifunctional coatings. Science. $318,426-430$

[12] Lee, H., Rho, J., Messersmith, P.B., 2009. Facile conjugation of biomolecules onto surfaces via mussel adhesive protein inspired coatings. Adv. Mat. 21, 431-434.

[13] Liebscher, J., Mrowczynski, R., Scheidt, H.A., Filip, C., Hadade, N.D., Turcu, R., Bende, A., 2013. Structure of polydopamine: a never-ending story?. Langmuir. 29, 10539-10548.

[14] Li, S.F., Fan, Y.H., Hu, R.F., Wu, W.T., 2011. Pseudomonas cepacia lipase immobilized onto the electrospun pan nanofibrous membranes for biodiesel production from soybean oil. J. Mol. Catal. B: Enzym. 72, 4045.

[15] Mahamuni, N.N., Adewuyi, Y.G., 2009. Fourier transform infrared spectroscopy (FTIR) method to monitor soy biodiesel and soybean oil in transesterification reactions, petrodiesel-biodiesel blends and blend adulteration with soy oil. Energy Fuels. 23, 3773-3782.

[16] Mateo, C., Palomo, J.M., Fernandes-Lorente, G., Guisan, J.M., Fernanes-Lafuente, R., 2007. Improvement of enzyme activity, stability and selectivity via immobilization techniques. Enzyme Microb. Tech. 40, 1451-1463

[17] Moser, B.R., 2011. Biodiesel production, properties, and feedstocks, in: Tomes, D., Lakshmanan, P., Sonstad, D. (Eds.), Biofuels. New York, Springer, pp. 285-347.

[18] Netto, C.G.C.M., Andrade, L.H., Toma, H.E., 2009. Enantioselective transesterification catalysis by Candida antarctica lipase immobilized on superparamagnetic nanoparticles. Tetrahedron: Asymmetry. 20, 2299-2304

[19] Netto, C.G.C.M., Nakamatsu, E.H., Netto, L.E.S., Novak, M.A., Zuin, A., Nakamura, M., Araki, K., Toma, H.E., 2011. Catalytic properties of thioredoxin immobilized on superparamagnetic nanoparticles. J. Inorg. Biochem. 105, 738-744.

[20] Netto, C.G.C.M., Nakamura, M., Andrade, L.H., Toma, H. E., 2012. Improving the catalytic activity of formate dehydrogenase from Candida boidinii by using magnetic nanoparticles. J. Mol. Catal. B: Enzym. 84, 139-143.
[21] Netto, C.G.C.M., Toma, H.E., Andrade, L.H., 2013 Superparamagnetic nanoparticles as versatile and supporting materials for enzymes. J. Mol. Catal. B: Enzym. 85-86, 71-92.

[22] Netto, C.G.C.M., Andrade, L.H., Toma, H.E., 2015. Association of Pseudomonas putida formaldehyde dehydrogenase with superparamagnetic nanoparticles: an effective way of improving the enzyme stability, performance and recycling. New J. Chem. 39, 2162-2167.

[23] Rebelo, L.P., Netto, C.G.C.M., Toma, H.E., Andrade, L.H., 2010. Enzymatic kinetic resolution of (rs)-1-(phenyl)ethanols by Burkholderia cepacia lipase immobilized on magnetic nanoparticles. J. Braz. Chem. Soc. 21, 1537-1542.

[24] Ren, Y., Rivera, J.G., He, L., Kulkarni, H., Lee, D.K., Messersmith, P.D., 2011. Facile, high efficiency immobilization of lipase enzyme on magnetic iron oxide nanoparticles via a biomimetic coating. BMC Biotech. 11, 63. DOI: 10.1186/1472-6750-11-63.

[25] Rodrigues, R.C., Ortiz, C., Berenguer-Murcia, A., Torres, R., Fernandez-Lafuente, R., 2013. Modifying enzyme activity and selectivity by immobilization. Chem. Soc. Rev. 42, 6290-6307.

[26] Sharp, C.A., Howell, S.A., Jobe, J., 2000. The effect of biodiesel fuels on transient emissions from modern diesel engines, Part II, unregulated emissions and chemical characterization. SAE Technical Paper. No. 2000-01-1968.

[27] Srivastava, A., Prasad, A.R., 2000. Triglycerides-based diesel fuels Renew. Sust. Energy Rev. 4, 111-133.

[28] Straathof, A.J., Panke, S., Schmid, A., 2002. The production of fine chemicals by biotransformations. Curr. Opin. Biotechnol. 13, 548556.

[29] Tan, T., Lu, J.K., Nie, K.L., Deng, L., Wang, F., 2010. Biodiesel production with immobilised lipase: a review. Biotechnol. Adv. 26 628-634.

[30] Verma, M.L., Barrow, C.J., Puri, M., 2013. Nanobiotechnology as a novel paradigm for enzyme immobilisation and stabilisation with potential applications in biodiesel production. Appl. Microbiol Biotechnol. 97, 23-39.

[31] Wang, X., Liu, X., Zhao, C., Ding, Y., Xu, P., 2011. Biodiese production in packed-bed reactors using lipase-nanoparticle biocomposite. Bioresour. Technol. 102, 6352-6355.

[32] Xu, C., Xu, K., Gu, H., Zheng, R., Liu, H., Zhang, X., Guo, Z., Xu, B., 2004. Dopamine as a robust anchor to immobilize functiona molecules on the iron oxide shell of magnetic nanoparticles. J. Am. Chem. Soc. 126, 9938-9939.

[33] Yamaura, M., Camilo, R.L., Sampaio, L.C., Macedo, M.A., Nakamura, M., Toma, H.E., 2004. Preparation and characterization of (3-aminopropyl) triethoxysilane coated magnetite nanoparticles. J. Magn. Magn. Mater. 279, 210-217.

[34] Yücel, Y., Demir, C., Dizge, N., Keskinler, B., 2011. Lipase immobilization and production of fatty acid methyl esters from canola oil using immobilized lipase. Biomass Bioenergy. 35, 1496 1501

[35] Zhang, F., Adachi, D., Tamalampudi, S., Kondo, A., Tominaga, K., 2013. Real-time monitoring of the transesterification of soybean oil and methanol by fourier transform infrared spectroscopy. Energy Fuels. 27, 5957-5961. 